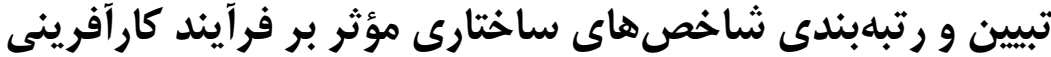

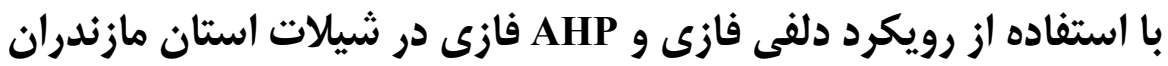

\author{
حسين صمدى ميار كلائى ' و حمزه صمدى ميار كلائى '

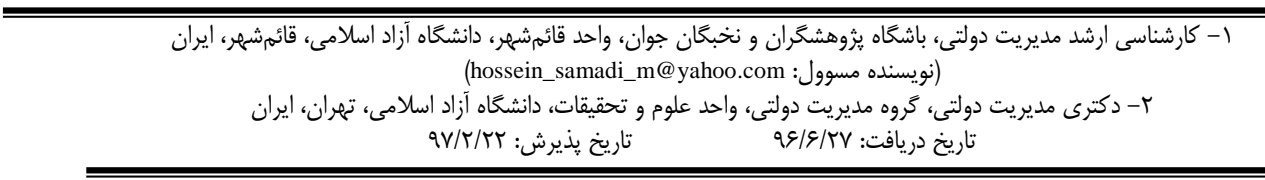

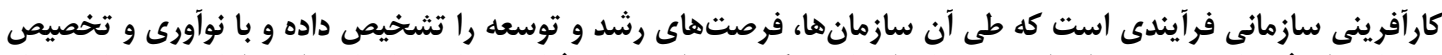

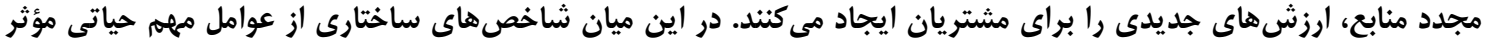

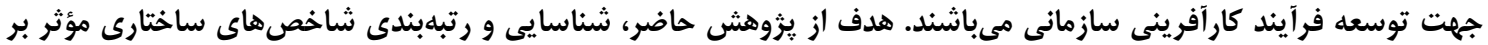

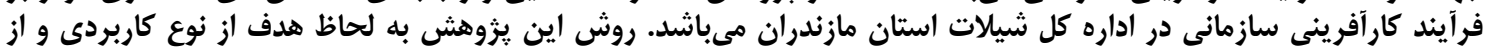

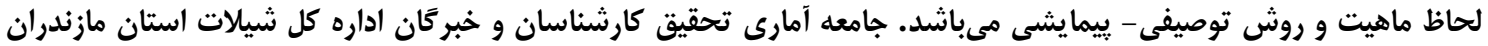

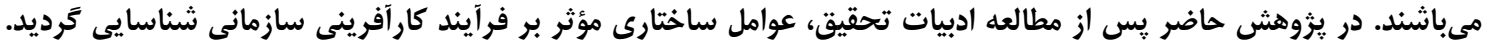

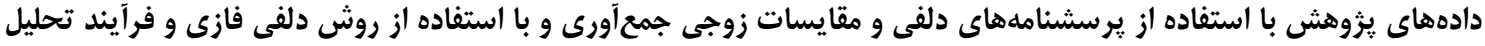

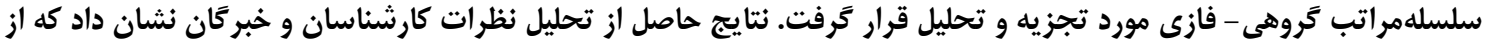

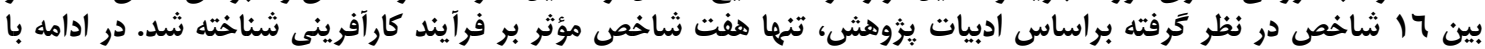

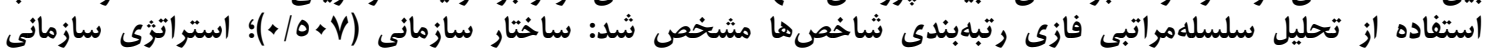

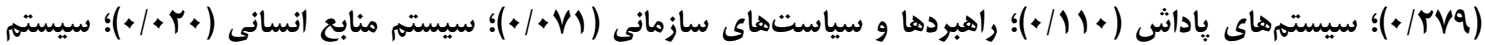

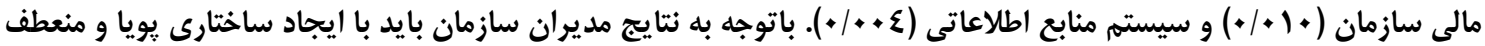

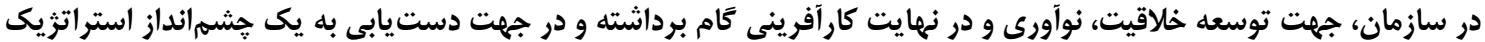

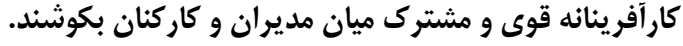

وازههاى كليدى: كارآفرينى سازمانى، شيلات استان مازندران، دلفى فازى، تحليل سلسلهمراتبى فازى

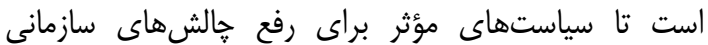

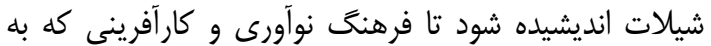

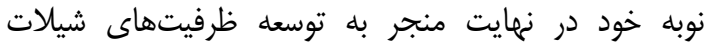

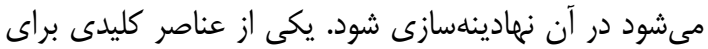

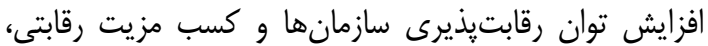

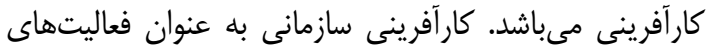

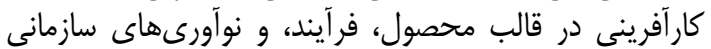

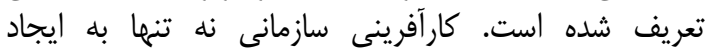

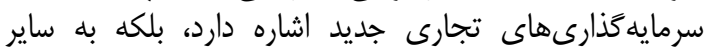

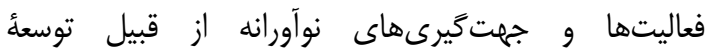

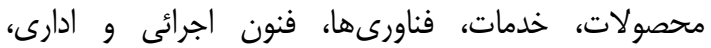

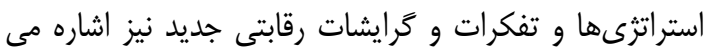

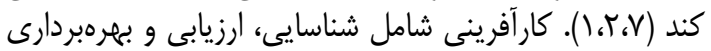

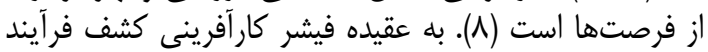

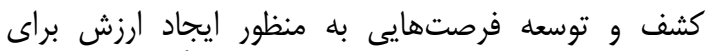

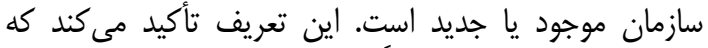

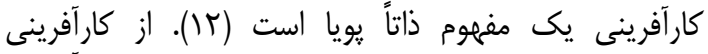
تقسيمبندى هاى مختلفى ارائه شده است. علاوه بر بارئ كارآفرينى

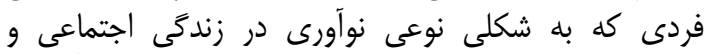

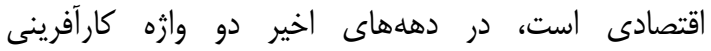
درونسازمانى و كارآفرينى شركتى نيز به ادرئ ادييات كارآفرينى معرفى شدهاند. علت رواج اين مفاهيه هماهنگ محيط اجتماعى و اقتصادى بوده است (YN). محققان معان معتقدند
امروزه نظامهاى مختلف اجتماعى و سازمانى با خالشها

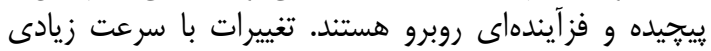

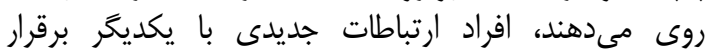

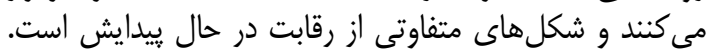

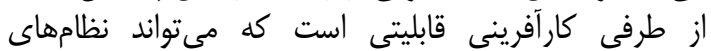

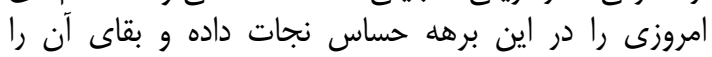

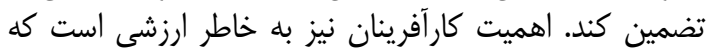

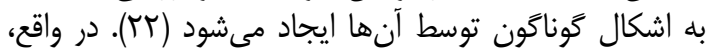

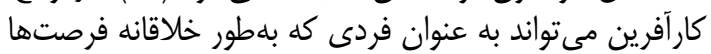

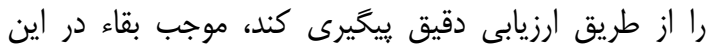

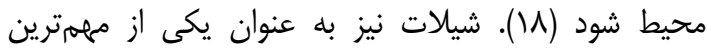

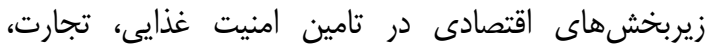

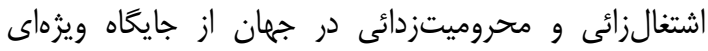

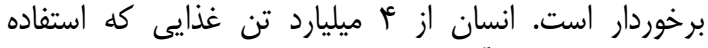

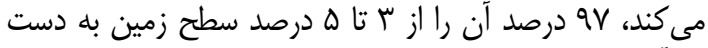

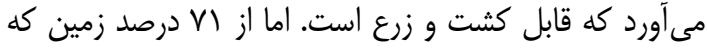

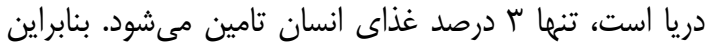

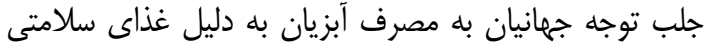

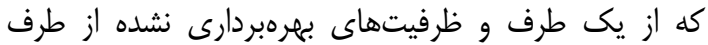

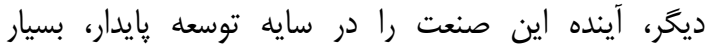

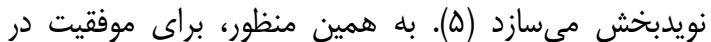
بمرهبردارى كامل از ظرفيتهاى توسعه صنعت شيلات منات لازم 


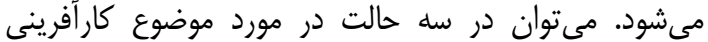

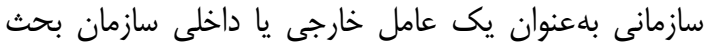

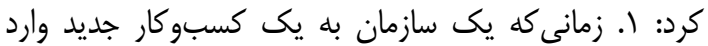

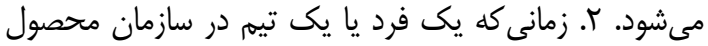

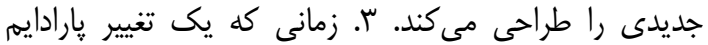

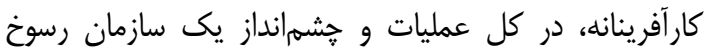

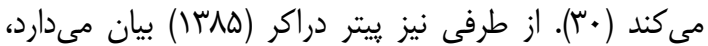

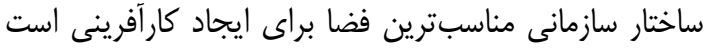

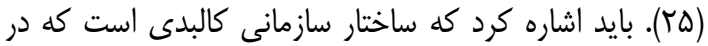

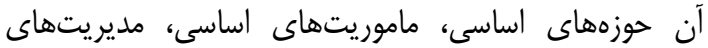

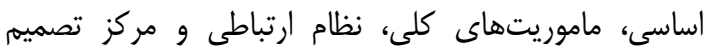

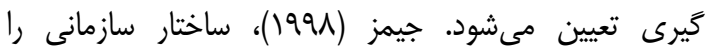

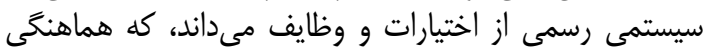

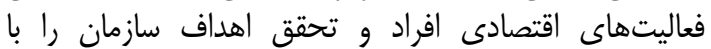

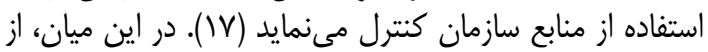

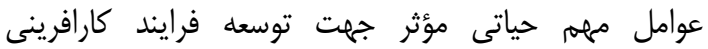

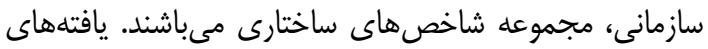

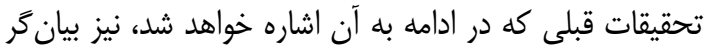

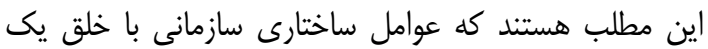

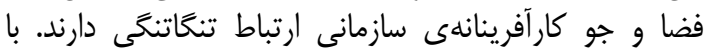

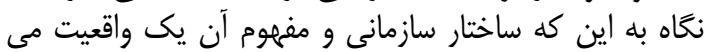

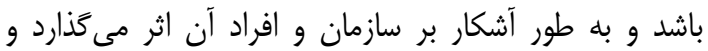

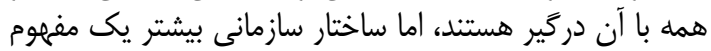

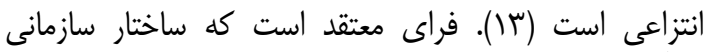

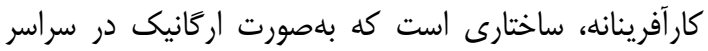

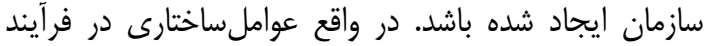

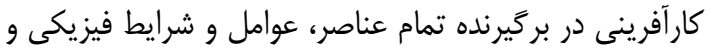

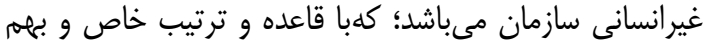

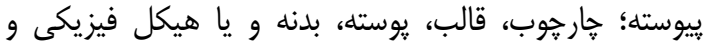

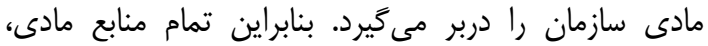

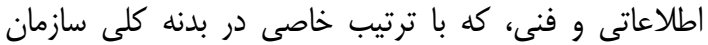

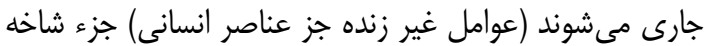

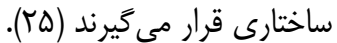

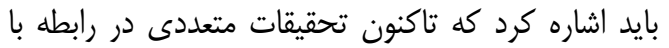

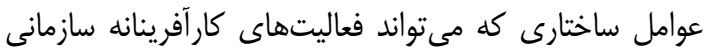

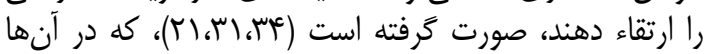

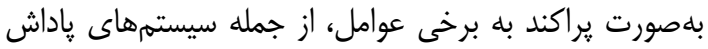

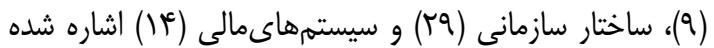

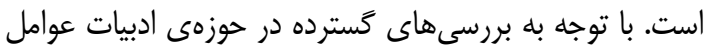

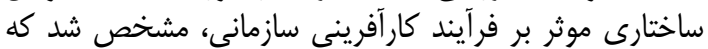

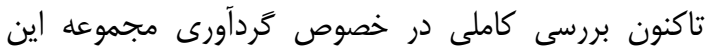

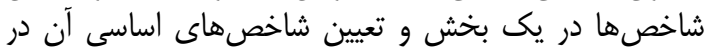

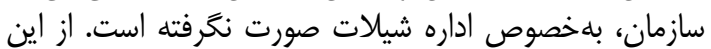

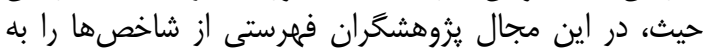

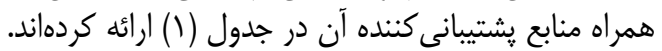

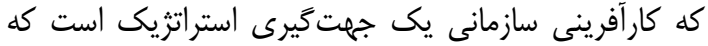

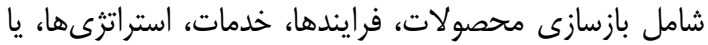

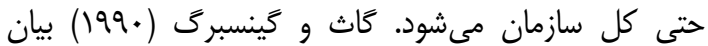
كردند كه كارآفرينى سازمانى فرآيندى است كأن كه شركتها

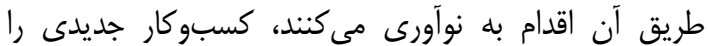

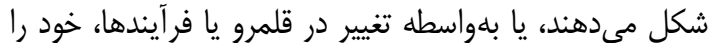

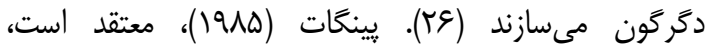

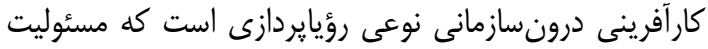

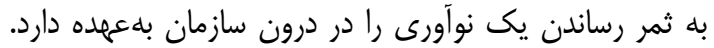

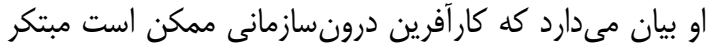

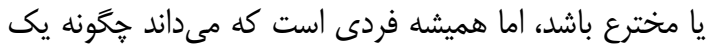

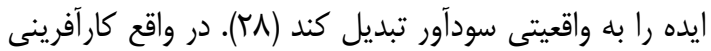

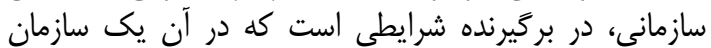

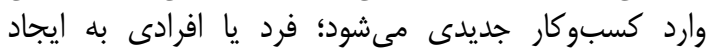

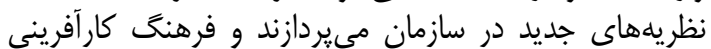

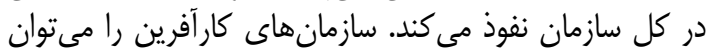

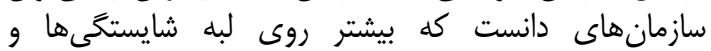

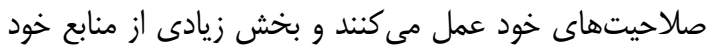

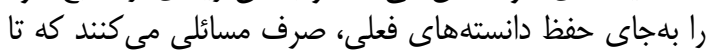

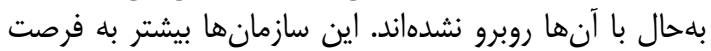

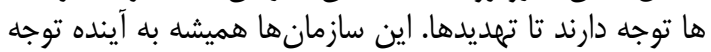

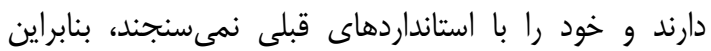

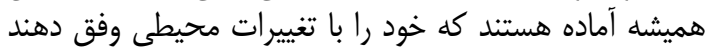

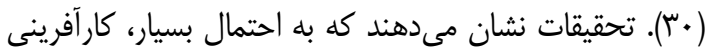

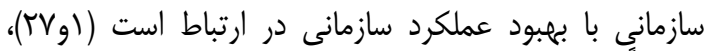

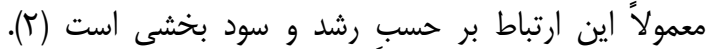

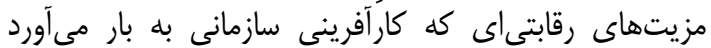

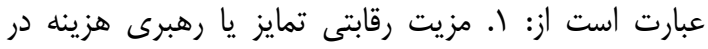

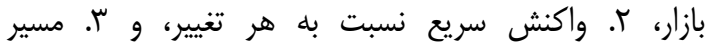

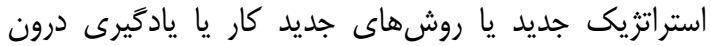

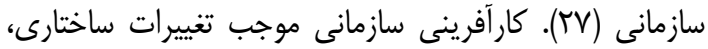

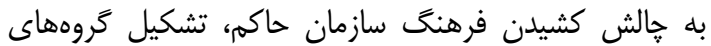

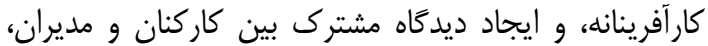

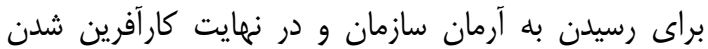

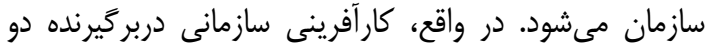

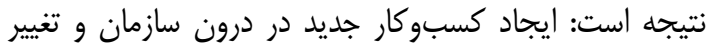

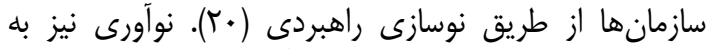

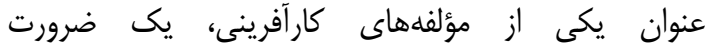

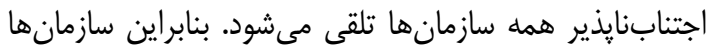

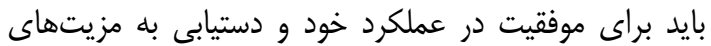

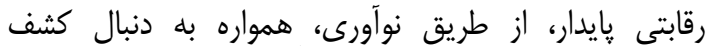

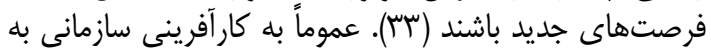

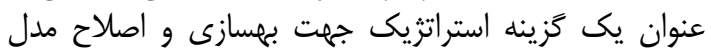

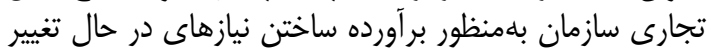

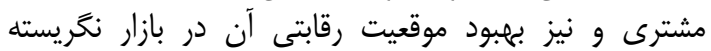


Table 1. Effective Structural Indicators on the Organizational Entrepreneurship

جدول 1 - عوامل ساختارى مؤثر بر كار آفرينى سازمانى

\begin{tabular}{|c|c|}
\hline 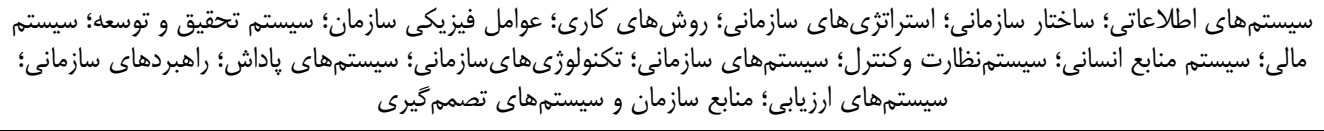 & $\begin{array}{l}\vdots \\
3: \\
9\end{array}$ \\
\hline 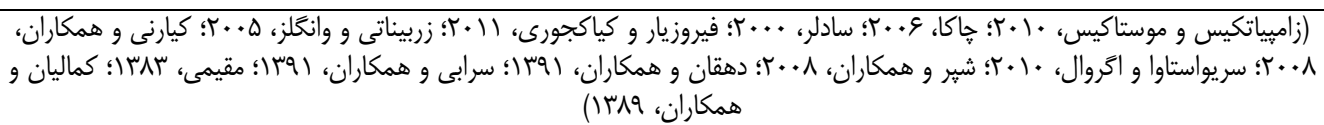 & \begin{tabular}{l}
3 \\
$\vdots$ \\
\hdashline
\end{tabular} \\
\hline
\end{tabular}

مازندران، كه آشنايى بالايى با مسائل كارآفرينى سازمانى و

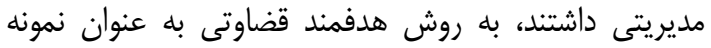

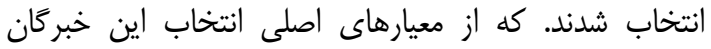

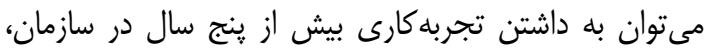

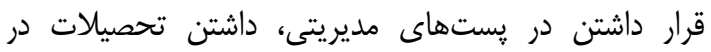

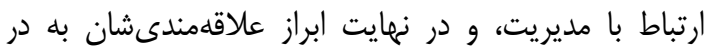

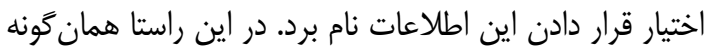

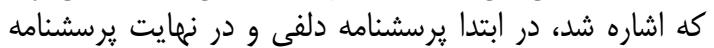

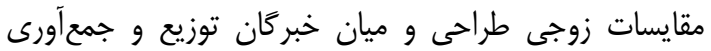

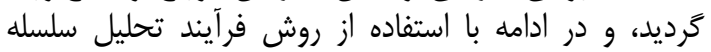

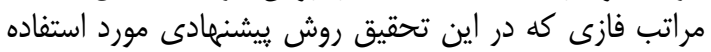

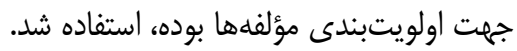

$$
\text { رويكرد دلفى فازى }
$$

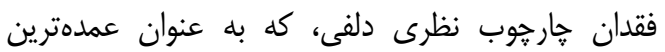

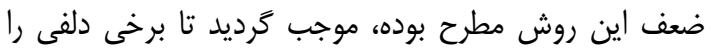

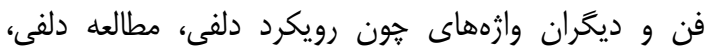

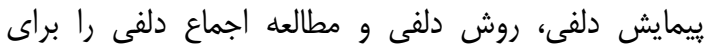

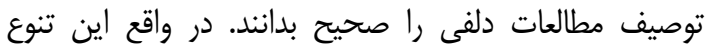

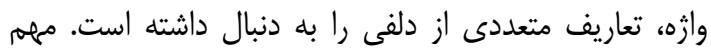

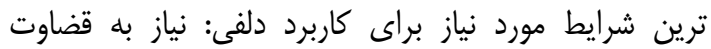

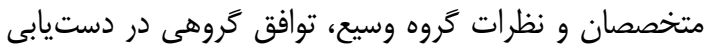

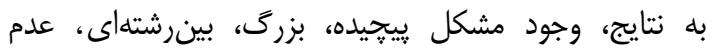

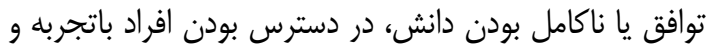

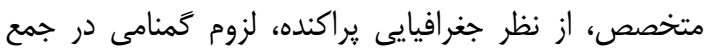

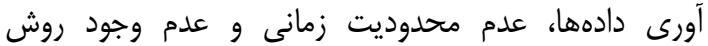

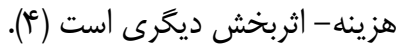

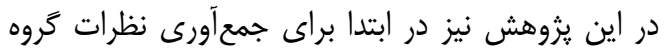

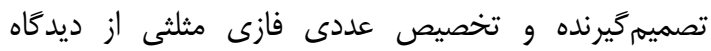

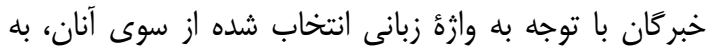

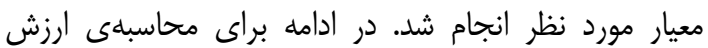

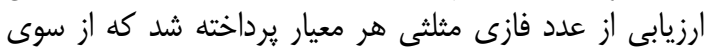

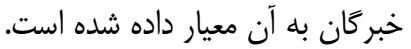

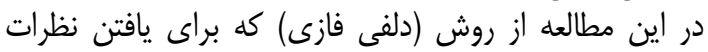

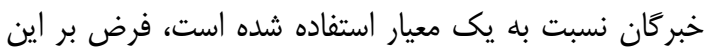

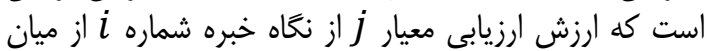
$n$ $i=1,2, \ldots, n$ با

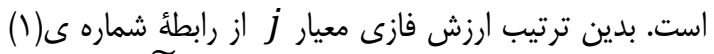
محاسبه مى شود كه برابر
با اين نخاه علاوه بر اين عوامل، متغيرهاى ساختارى

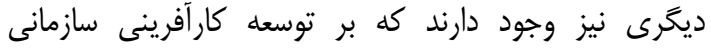

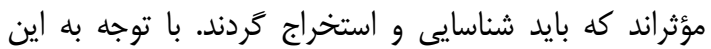

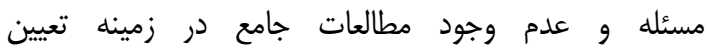

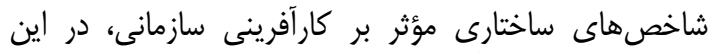

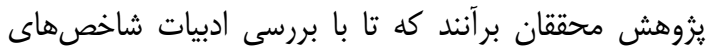

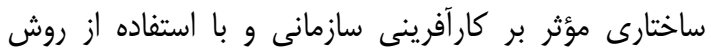

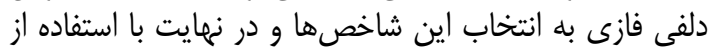

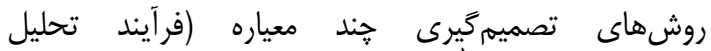

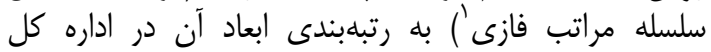

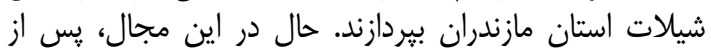

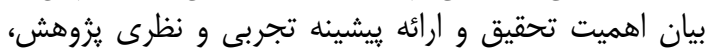

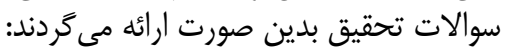

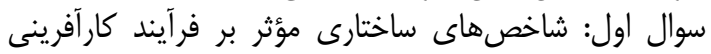

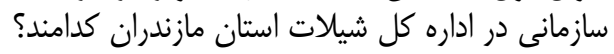

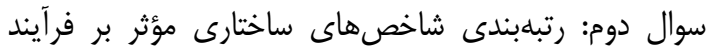

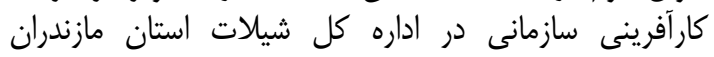

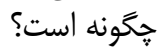

\section{مواد و روشها}

يروهش حاضر به لحاظ هدف از نوع كاربردى و از لحاظ

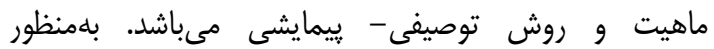

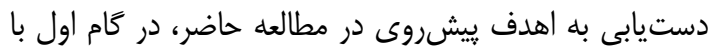

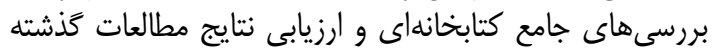

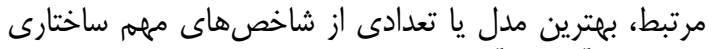

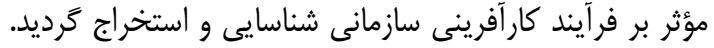

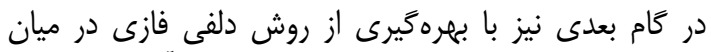

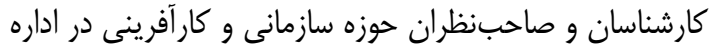

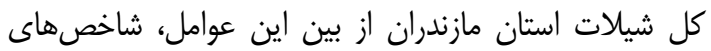

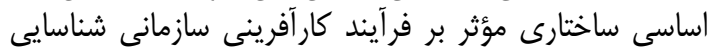

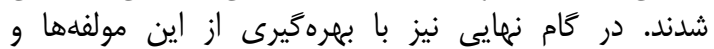

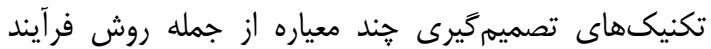

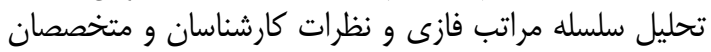

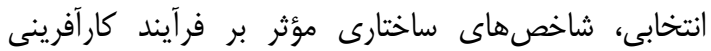

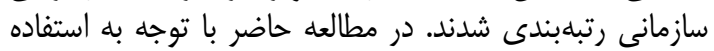

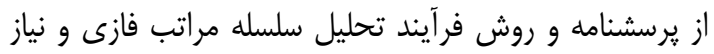

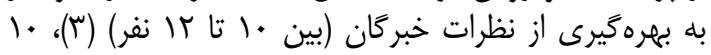

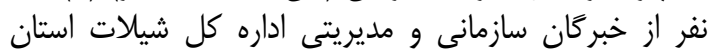


$a_{j}=\min \left\{a_{i j}\right\}$

$b_{j}=\frac{1}{n} \sum_{i=1}^{n} b_{i j}$

$c_{j}=\max \left\{c_{i j}\right\}$

$S_{j}=\frac{a_{j}+4 b_{j}+c_{j}}{6} \quad, j=1,2, \ldots, m$

براى دىفازىسازى از رابطهى (ז) استفاده مىشود.

كزينههاى مختلف، ناتوان است. براى رفع مشكلات بالات

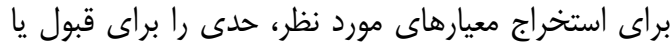
فرآيند تحليل سلسلهمراتب فازى إنى براى حل مسائ مسائل سلسله

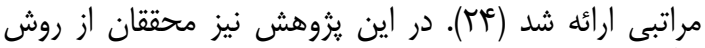

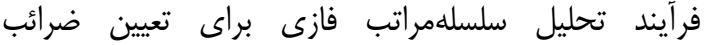

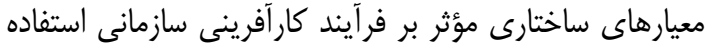

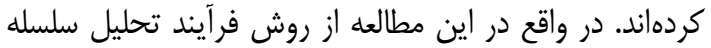

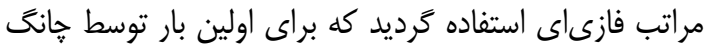

ارائه شده است (·) (1).

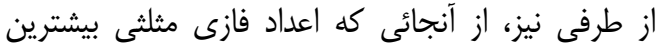

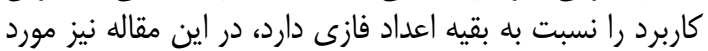

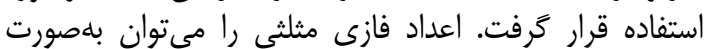

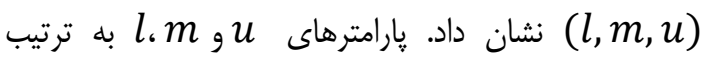

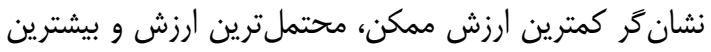

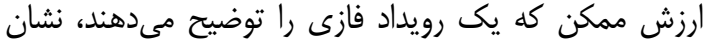

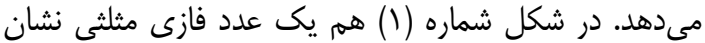

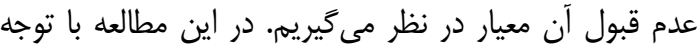

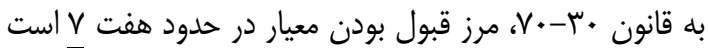

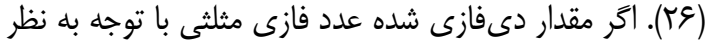

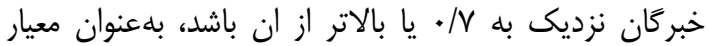

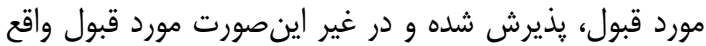
$S_{j} \geq a \quad, \quad S_{j}<a$

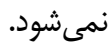
تكنيك تحليل سلسلهمر اتبى تروهيى - فازي

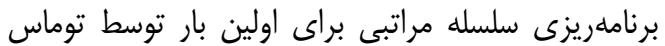

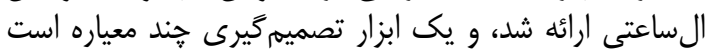

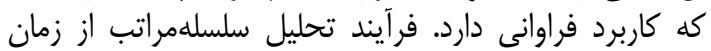

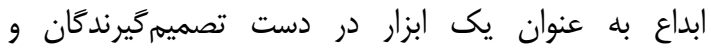

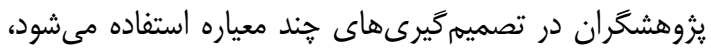

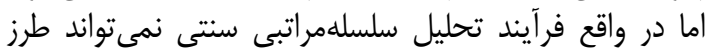

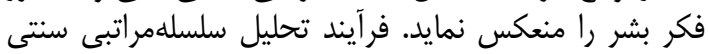
در بيان ارزشهاى دقيق عقايد تصميمَيرنده در مقايسهى

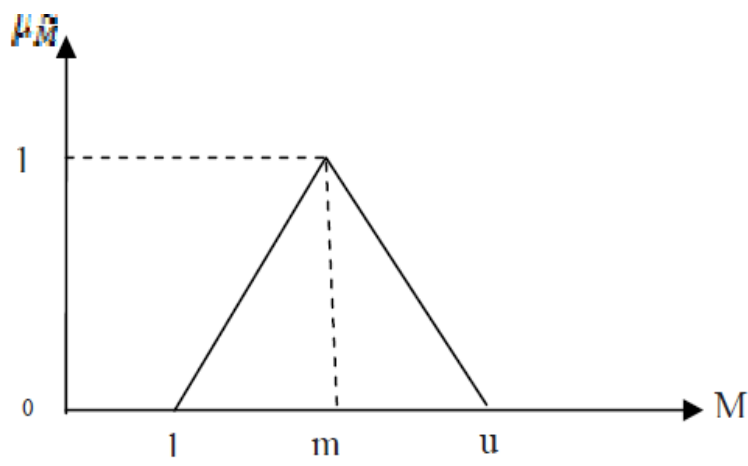

شكل - -

Figure 1. $\widetilde{M}$ is a Triangular Fuzzy Number 
مقايسات فازى، ماتريس مقايسات زوجى (㳊) با استفاده از

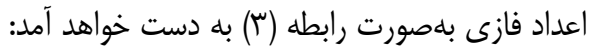

براى تحليل سلسلهمراتب گروهى فازى، بعد از رسم

نمودار سلسله مراتبى و تعريف اعداد فازى بهمنظور انجام

$\tilde{A}=\left[\begin{array}{cccc}1 & \tilde{a}_{12} & \cdots & \tilde{a}_{1 n} \\ \tilde{a}_{21} & 1 & \cdots & \tilde{a}_{2 n} \\ \vdots & \vdots & \ddots & \vdots \\ \tilde{a}_{n 1} & \tilde{a}_{n 2} & \cdots & 1\end{array}\right]=\left[\begin{array}{cccc}1 & \tilde{a}_{12} & \cdots & \tilde{a}_{1 n} \\ 1 / \tilde{a}_{21} & 1 & \cdots & \tilde{a}_{2 n} \\ \vdots & \vdots & \ddots & \vdots \\ 1 / \tilde{a}_{n 1} & 1 / \tilde{a}_{n 2} & \cdots & 1\end{array}\right]$

$\tilde{a}_{i j}= \begin{cases}1 & i=j \\ \tilde{1}, \tilde{3}, \tilde{5}, \tilde{7}, \tilde{9} \text { or } \tilde{1}^{-1}, \tilde{3}^{-1}, \tilde{5}^{-1}, \tilde{7}^{-1}, \tilde{9}^{-1} & i \neq j\end{cases}$

در واقع، ماتريس فوق حاوى اعداد زير است:

$\tilde{a}_{i j}=L_{i j}, M_{i j}, U_{i j}$

نظرسنجىها (U) است. محاسبه $S_{i}$ براى هر يك از سطرهاى

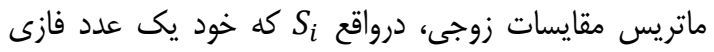
مثلثى است از رابطه (ه) محاسبه مى شود:

$S_{i}=\sum_{j=1}^{m} M_{g i}^{j} \otimes\left[\sum_{i=1}^{n} \sum_{j=1}^{m} M_{g i}^{j}\right]^{-1}$

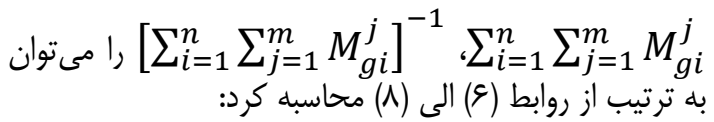

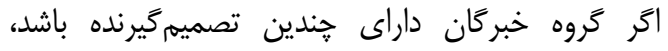

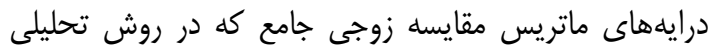

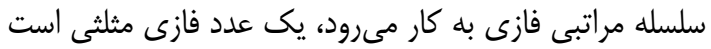

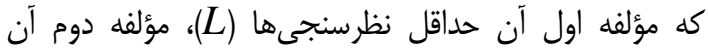

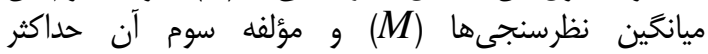

در اين رابطه أ بيانكر شماره سطر و ز بيانكر شماره ستون است. مقائه مقايسه زوجى

$\sum_{j=1}^{m} M_{g i}^{j}=\left(\sum_{j=1}^{m} l_{j}, \sum_{j=1}^{m} m_{j}, \sum_{j=1}^{m} u_{j}\right)$

$\sum_{i=1}^{n} \sum_{j=1}^{m} M_{g i}^{j}=\left(\sum_{i=1}^{n} l_{i}, \sum_{i=1}^{n} m_{i}, \sum_{i=1}^{n} u_{i}\right)$

$\left[\sum_{i=1}^{n} \sum_{j=1}^{m} M_{g i}^{j}\right]^{-1}=\left(\frac{1}{\sum_{i=1}^{n} u i}, \frac{1}{\sum_{i=1}^{n} m i}, \frac{1}{\sum_{i=1}^{n} l i}\right)$

در روابط بالا

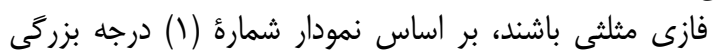
M نسبت به $M_{1}$

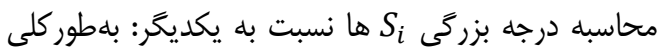

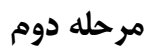
اكر

$V\left(M_{2} \geq M_{1}\right)=\operatorname{hgt}\left(M_{1} \cap M_{2}\right)=M_{m_{2}}(d)=\left\{\begin{array}{cc}1, & \text { if } M_{2} \geq M_{1} \\ 0, & \text { if } l_{1} \geq u_{2} \\ \frac{l_{1}-u_{2}}{\left(m_{2}-u_{2}\right)-\left(m_{1}-l_{1}\right)} & \text { otherwise }\end{array}\right\}$ (q) 
$V\left(M \geq M_{1}, M_{2}, \ldots, M_{k}\right)=V\left[\left(M \geq M_{1}\right)\right.$ and $\left(M \geq M_{2}\right)$ and $\ldots$ and $\left(M \geq M_{k}\right]$ $=\operatorname{Min} V\left(M \geq M_{i}\right), \quad i=1,2,3, \ldots, \mathrm{k}$

براى محاسبه وزن معيارها و گزينهها در ماتريسهاى مقايسه زوجى از رابطه (1) استفاده مى گردد: $d^{\prime}\left(A_{i}\right)=\operatorname{Min} V\left(S_{i} \geq S_{k}\right)$ for $k=1,2, \ldots, n ; k \neq i$.

بنابراين بردار وزن نرماليزه نشده بلهورت رابطه (T/) خواهد بود: $W^{\prime}=\left(d^{\prime}\left(A_{1}\right), d^{\prime}\left(A_{2}\right), \ldots, d^{\prime}\left(A_{n}\right)\right)^{T} \quad A_{i}=(i=1,2, \ldots, n)$

مرحله جهمارم

محاسبه بردار وزن نهائى؛ براى محاسبه بردار وزن نهائى بايد بردار وزن محاسبهشده در مرحله قبل را نرماليزه كرد. بنابراين: $W=\left(d\left(A_{1}\right), d\left(A_{2}\right), \ldots, d\left(A_{n}\right)\right)^{T}$

براى ماتريس هاى مقايسات زوجى فازى

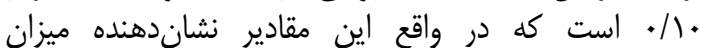

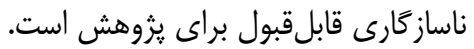
محاسبهى ماتريس

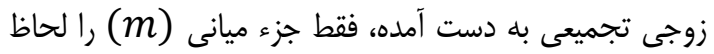
كرده و ماتريسى را استخراج مى كنيهم. نرمالايز كردن ماتريس

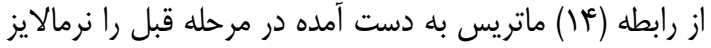
و وزن ( ) هر كدام از عوامل محاسبه مىشود:

محاسبهى ساز كارى ماتريسهاى مقايسات زوجى كاكوس

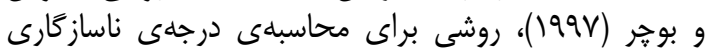

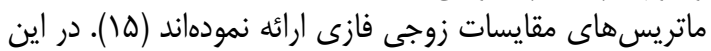

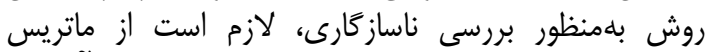

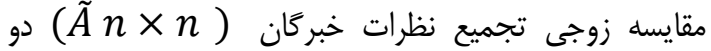
ماتريس مجزا تشكيل شود:

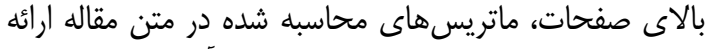

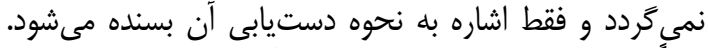

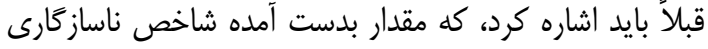
$w^{m}=\left[w_{i}^{m}\right] \quad$ where $\quad w_{i}^{m}=\frac{1}{n} \sum_{j=1}^{n} \frac{a_{i j m}}{\sum_{i=1}^{n} a_{i j m}}$

ماتريس تقسيم و با استفاده از روابط (Dار) الى (IV) شاخص

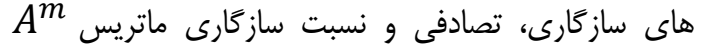
محاسبه و تعيين مى

$\lambda_{\max }^{m}=\frac{1}{n} \sum_{i=1}^{n} \sum_{j=1}^{n} a_{i j m}\left(w_{j}^{m} / w_{i}^{m}\right)$

$C I^{m}=\frac{\left(\lambda_{\max }^{m}-n\right)}{(n-1)}$

$C R=C I / R I$

محاسبهى ماتريس

$$
A^{g}=\sqrt{\mathrm{a}_{\mathrm{ijl}} \cdot \mathrm{a}_{\mathrm{iju}}}
$$

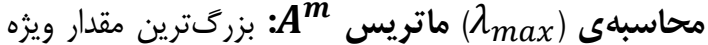

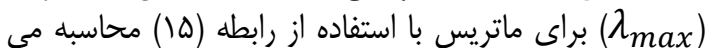
شود. بدين منظور، تكتى اجز براء ماتريس مىشود. در نهايت، مجموع حاصله را بر n ميا همان ابعاد حلد يايين اعداد فازى مثلثى ايجاد مى شود: ماسيد

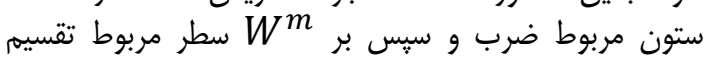


نرمالايز كردن ماتريس كدام از عوامل محاسبه مى كردد.

$w^{g}=\left[w_{i}^{g}\right] \quad$ where $\quad w_{i}^{g}=\frac{1}{n} \sum_{j=1}^{n} \frac{\sqrt{a_{i j u} \cdot a_{i j l}}}{\sum_{i=1}^{n} \sqrt{a_{i j u} \cdot a_{i j l}}}$

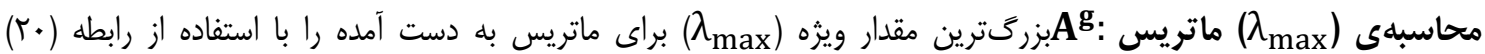

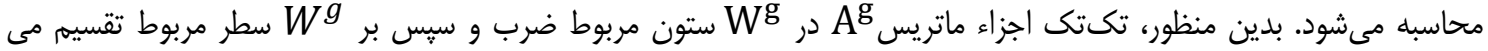

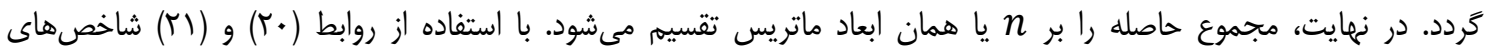

$\lambda_{\text {max }}^{g}=\frac{1}{n} \sum_{i=1}^{n} \sum_{j=1}^{n} \sqrt{a_{i j u} \cdot a_{i j l}}\left(w_{j}^{g} / w_{i}^{g}\right)$ ساز كارى، تصادفى و نسبت ساز كارى ماتريس

$C I^{g}=\frac{\left(\lambda_{\max }^{g}-n\right)}{(n-1)}, \quad C R=C I / R I$

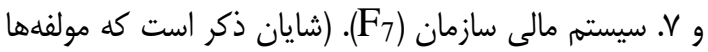

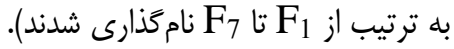
فر آيند تحليل سلسلهمراتب تروهى - فازى تانى مرحله اول

در اين مرحله شاخصهاى مورد نظر بلهورت بر برسشنامه

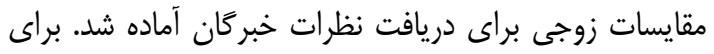

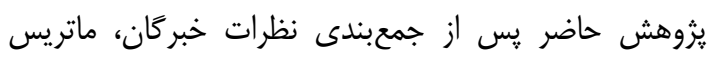
مقايسات زوجى كه درايههاى اين ماتريس اعداد فادئ فازى مثلثى

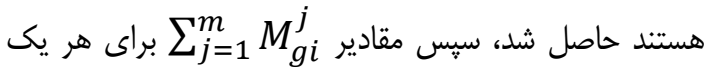

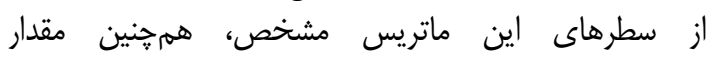
بر $S_{i}$ و $\left[\sum_{i=1}^{n} \sum_{j=1}^{m} M_{g i}^{j}\right]^{-1} ، \sum_{i=1}^{n} \sum_{j=1}^{m} M_{g i}^{j}$ هر يك از سطرهاى ماتريس مقايسات زوجى و درجه بز بزرخى

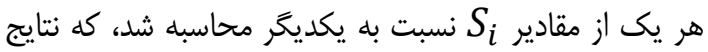
آن در جدول شماره ب آمده است.

نتايج و بحث

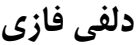

بررسى نظرات كارشناسان و خبركان در اين مطالعه حاكى

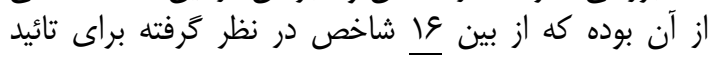

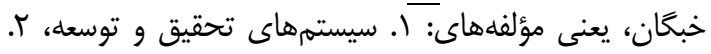

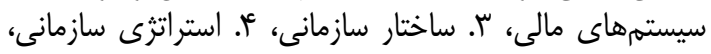

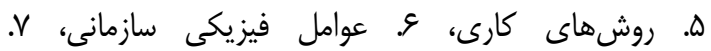

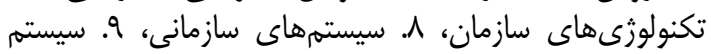

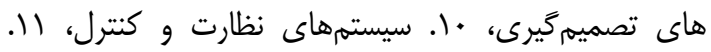

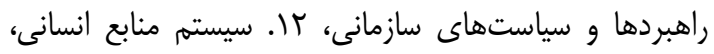

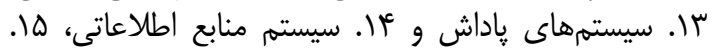

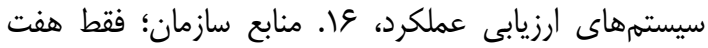

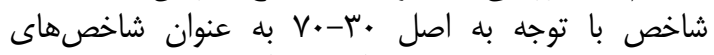
اساسى ساختارى مؤثر بر فرآيند كارآفرينى سازمانى تعيين

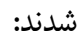

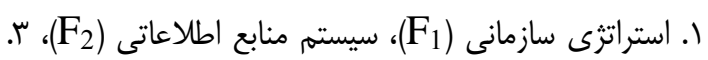

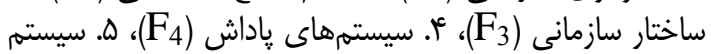

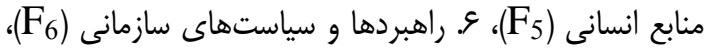

Table 2. The Sum Matrix of Experts' Opinions

جدول r- ماتريس تجميع نظرات خبركان

\begin{tabular}{|c|c|c|c|c|c|}
\hline عوامل & $\mathrm{F}_{1}$ & $\mathrm{~F}_{2}$ & *** & $\mathrm{F}_{6}$ & $\mathrm{~F}_{7}$ \\
\hline 1 & $(1.1 .1)$ & $\left(T / \backslash \Delta, r / T \Psi^{\prime}, r / \cdot q\right)$ & ******** & $(1 / 1), 1 / \Delta 1, K / 1 \cdot)$ & 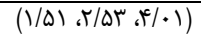 \\
\hline r & $(\cdot / T \& \Lambda, / T I \Phi, \cdot / \& V \Lambda)$ & $(1.1,1)$ & $* * * * * *$ & 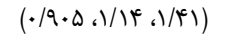 & $(I / T \backslash, T / 1 \Delta, r / \cdot \Delta)$ \\
\hline r & 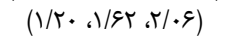 & $(\cdot / 8 \wedge) ، / 9 \vee \Delta, 1 / \% q)$ & ******\%* & $(T / 10, r / Q \cdot r / T / \uparrow)$ & $(1 / V) ، / D 1 ، / Q / 9)$ \\
\hline f & 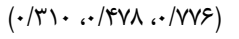 & $(\cdot / r q q ، \cdot / \Delta F \wedge ، / \Lambda F V)$ & ********* & 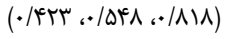 & $(\cdot / \mathrm{YT}$ ، I/M ، I/QI) \\
\hline$\Delta$ & 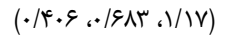 & $(\cdot / 4 I V ، . / 8 T V ، . / 911)$ & ******\%* & $(\cdot / \Delta \& D, \cdot / Q \subseteq \Phi, 1 / H F)$ & (I، $1 / \Delta T, r / \Lambda Q)$ \\
\hline द & 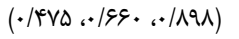 & 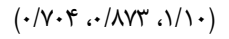 & $* * * * * \%$ & $(1,1,1)$ & 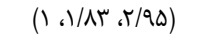 \\
\hline v & $(\cdot / T I 1 ، / K I S ، / \Delta g T)$ & $(\cdot /$ KTV . & ******** & ( ) & $(1,1,1)$ \\
\hline
\end{tabular}

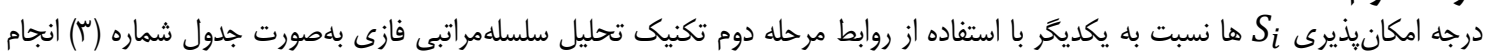


Table 3. The Amount of Fuzzy Component Expansion for the Main Factors

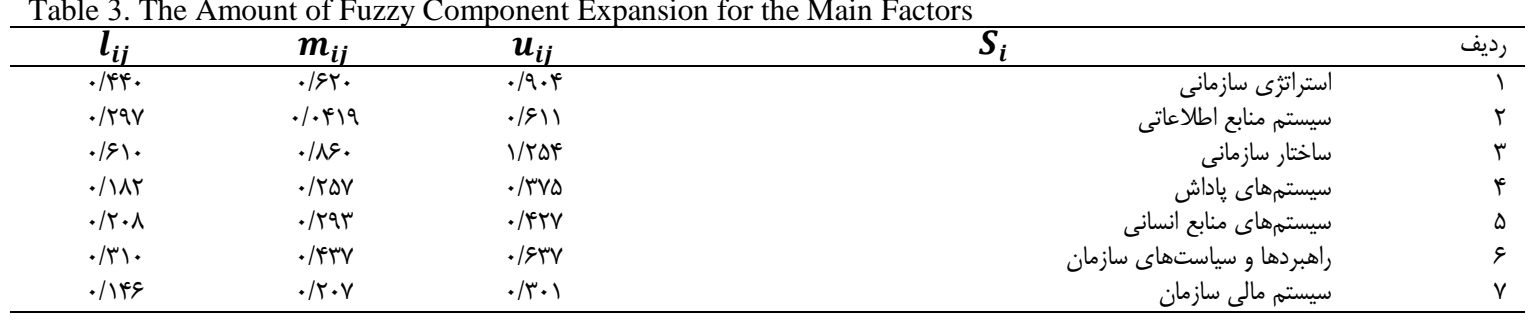

جدول ץ- مقدار بسط مر كب فازى عوامل اصلى مدف

مرحله سوم استفاده

با استفاده از روابط بيان شده، درجه امكانيذيرى براى حالتهاى دوتايى ممكن آشكار شد.

Table 4. The Possibility Degree for Possible Binary Modes

\begin{tabular}{|c|c|c|c|c|c|c|c|}
\hline عوامل & $\begin{array}{c}F_{1} \\
\mathrm{~V}\left(\mathrm{~S}_{\mathrm{cl}} \geq \mathrm{S}_{\mathrm{ci}}\right) \\
\end{array}$ & $\begin{array}{c}\mathrm{F}_{2} \\
\mathrm{~V}\left(\mathrm{~S}_{\mathrm{c} 2} \geq \mathrm{S}_{\mathrm{ci}}\right)\end{array}$ & $\begin{array}{c}\mathrm{F}_{3} \\
\mathrm{~V}\left(\mathrm{~S}_{\mathrm{c} 3} \geq \mathrm{S}_{\mathrm{ci}}\right)\end{array}$ & $\begin{array}{c}\mathrm{F}_{4} \\
\mathrm{~V}\left(\mathrm{~S}_{\mathrm{c} 4} \geq \mathrm{S}_{\mathrm{ci}}\right)\end{array}$ & $\begin{array}{c}\mathrm{F}_{5} \\
\mathrm{~V}\left(\mathrm{~S}_{\mathrm{c} 5} \geq \mathrm{S}_{\mathrm{ci}}\right)\end{array}$ & $\begin{array}{c}\mathrm{F}_{6} \\
\mathrm{~V}\left(\mathrm{~S}_{\mathrm{c} 6} \geq \mathrm{S}_{\mathrm{ci}}\right)\end{array}$ & $\begin{array}{c}\mathrm{F}_{7} \\
\mathrm{~V}\left(\mathrm{~S}_{\mathrm{c} 7} \geq \mathrm{S}_{\mathrm{ci}}\right)\end{array}$ \\
\hline$r$ & 1 & & 1 & . & $\cdot / \Delta \cdot \Lambda$ & 1 & .1 .199 \\
\hline f & 1 & 1 & 1 & & 1 & 1 & $\cdot / r \cdot r$ \\
\hline$\Delta$ & 1 & 1 & 1 & س H / & & 1 & . $/ \Delta T$. \\
\hline$q$ & 1 & עצ' & 1 & . / TEG & - / $4+q$ & & . /. ए人. \\
\hline
\end{tabular}

يافتهها حاكى از آن است كه از نظر خبر كان اداره كل شيلات

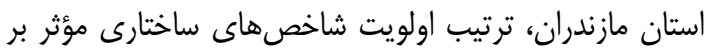

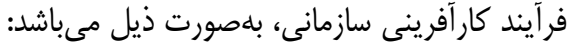

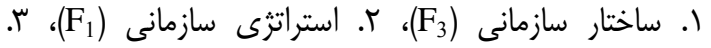

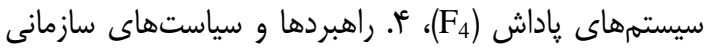

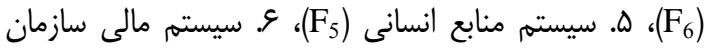

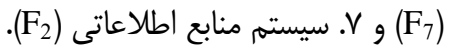

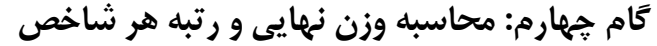

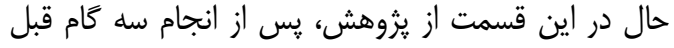

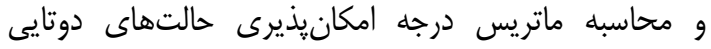

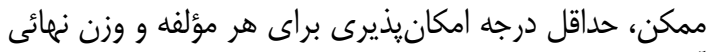

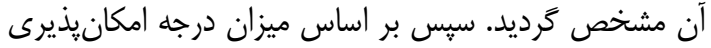

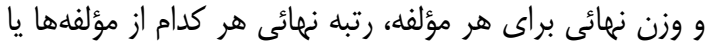

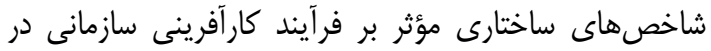

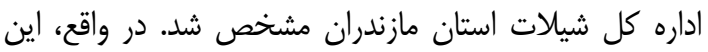

Table 5. The Terminal Weight and the Rank of Each Index

\begin{tabular}{cccccccccc}
\multicolumn{1}{l}{ Table 5. The Terminal Weight and the Rank of Each Index } \\
\hline
\end{tabular}

نتايج براى تبيين سوال دوم يزوهش مبنى بر اين كه:

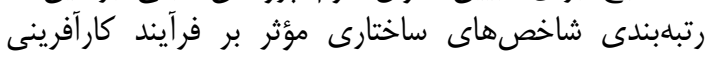

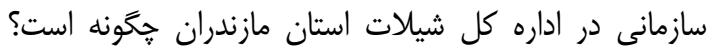

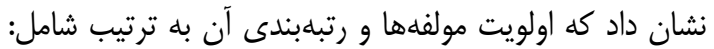

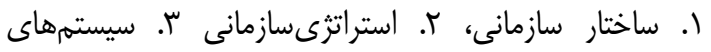

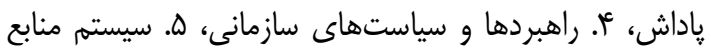

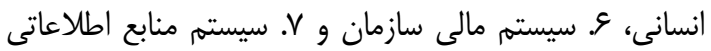

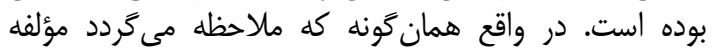

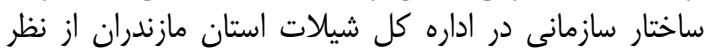

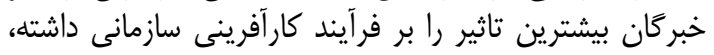

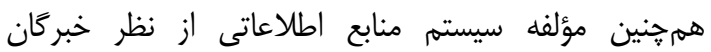

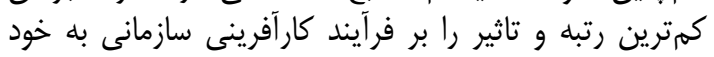
اختصاص داده است.

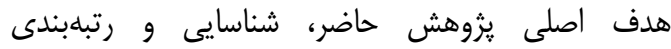

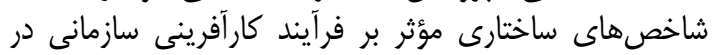

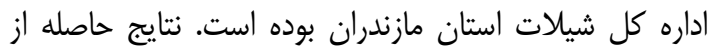

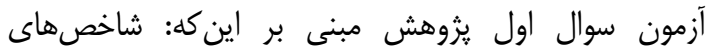

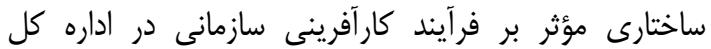

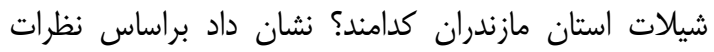

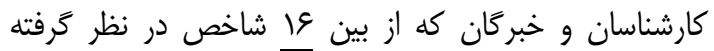

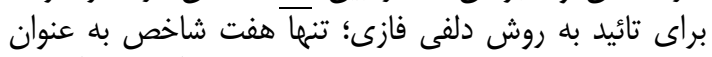

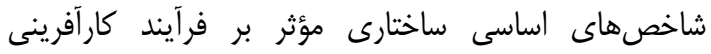

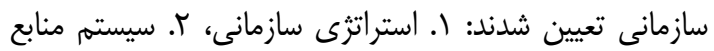

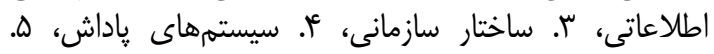

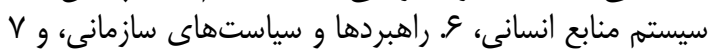
سيستم مالى سازمان. 
fأ. راهبردها و سياستهاى سازمانى: در واقع راهبردهاى

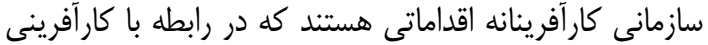

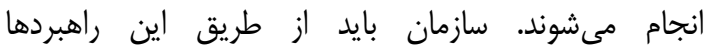

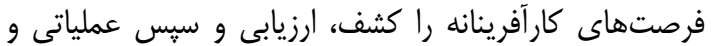
در نهايت بازخور دهد.

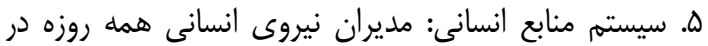

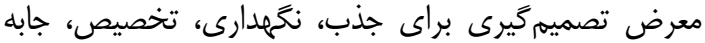

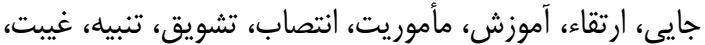

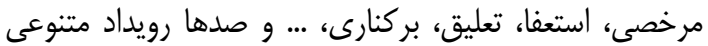

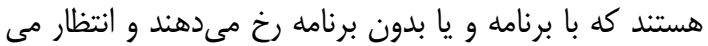

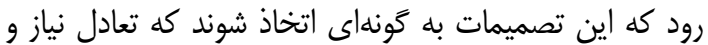
موجودى در هر بخش و هر تهر تخصص برقرار مانده، ضمن آنس آنكه

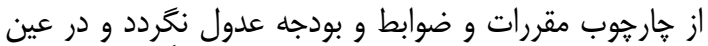

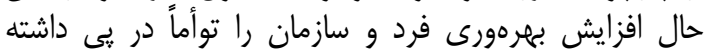

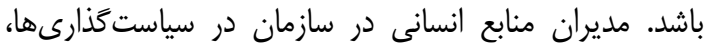

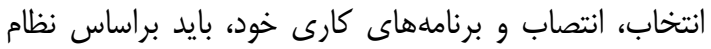

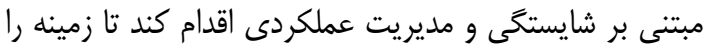
براى ايجاد جو نوآورى و كارآفرينى سازمانى ماتى محيا كنيند.

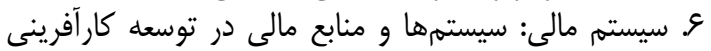

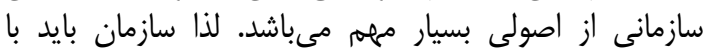

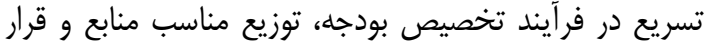

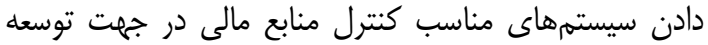
كارآفرينى سازمانى كام بردارد.

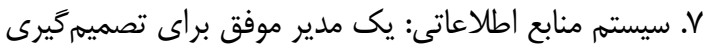

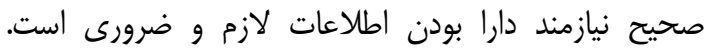

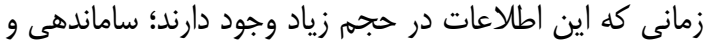

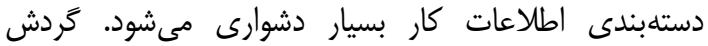

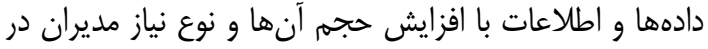

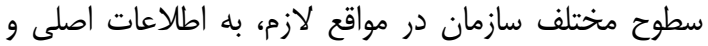

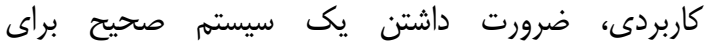

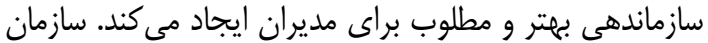

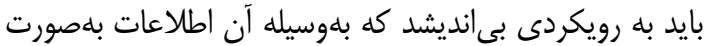

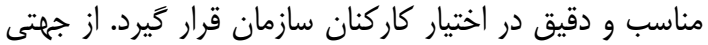

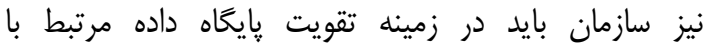

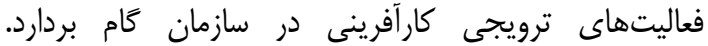

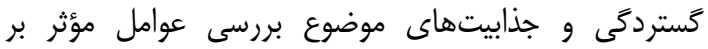

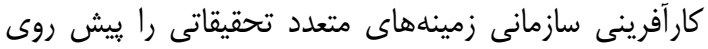

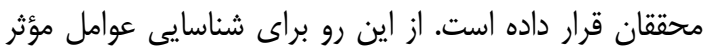

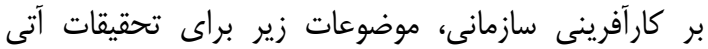

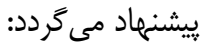

- جامع بودن مدل تحقيق حاضر: اولوديت مادبندى تاثير عوامل

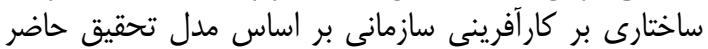

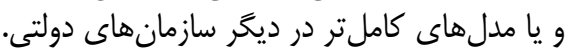

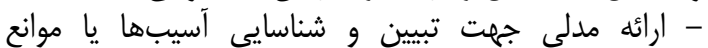

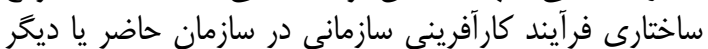
سازمانها. - بررسى نقش عازمانه عامل رفتارى و زمينهاى مؤثر بر فرآيند كارآفرينى سازمانى. تقرسى
در مورد مقايسه يافتههاى تحقيق حاضر با ساير يافته إنها

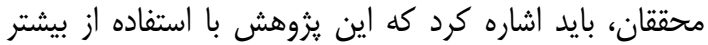

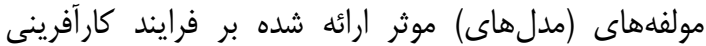

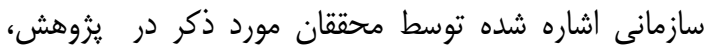

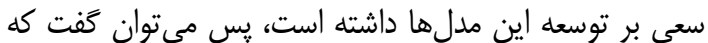

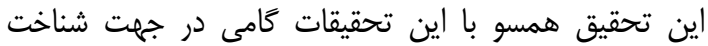

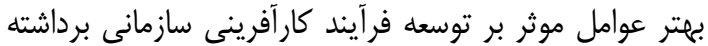

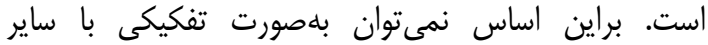

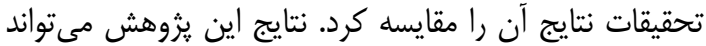

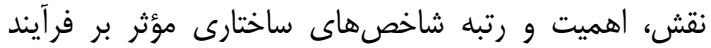

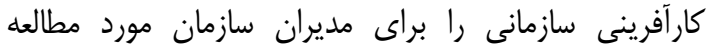

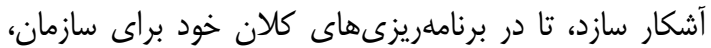

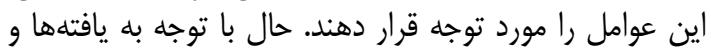

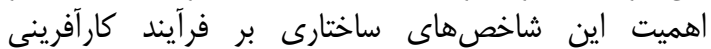

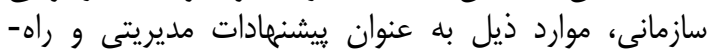

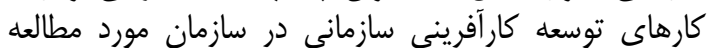

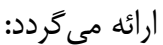

ا. ساختار سازمانى: نتايج نشان داد كه بيشترين تاثير را از از

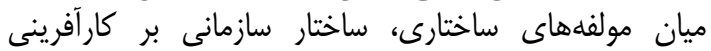

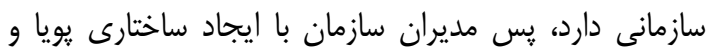

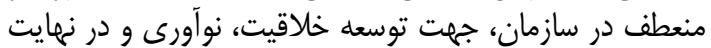

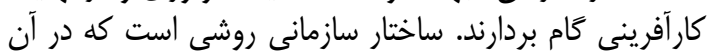

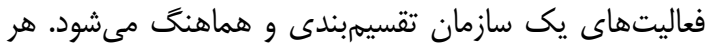

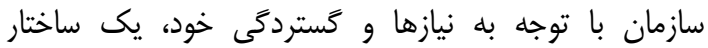

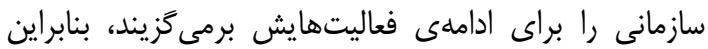

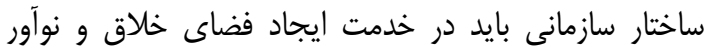
براى كاركنان باشد.

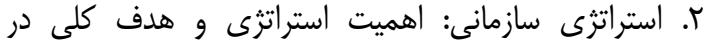

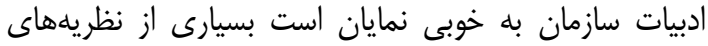

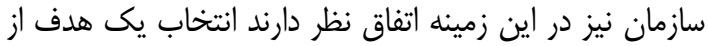

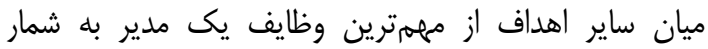

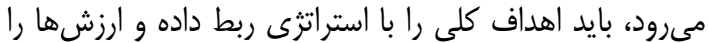

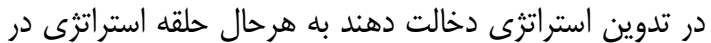

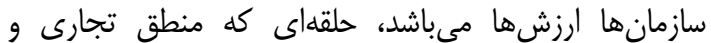

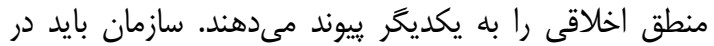

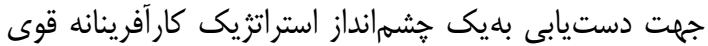

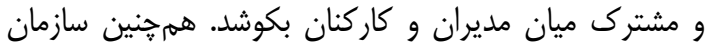

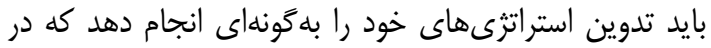
جهت شناسايى فرصتها كام بردارد.

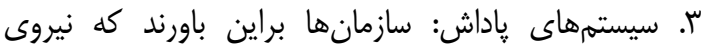

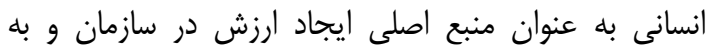

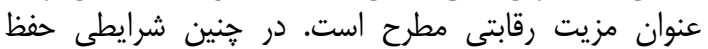

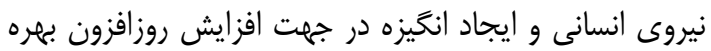

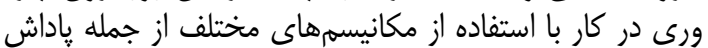

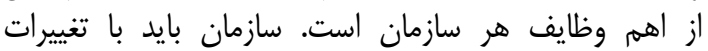

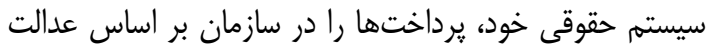

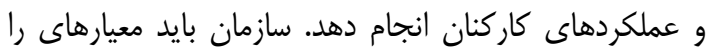

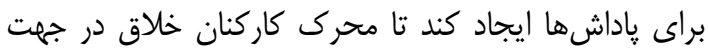
ابتكار بيشتر وكارآفرينى باشداد 


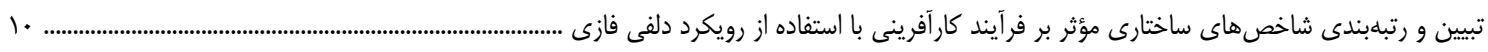
در نهايت محققين بر خود لازم مدى دانند تا از مسئولين و همكارى در اجراى يخوهش صميمانه تشكر و قدردانى نمايند.

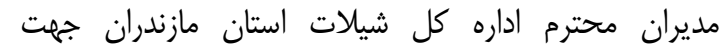

1. Antončič, B. and R.D. Hisrich. 2001. Entrepreneurship: Construct Refinement and Cross-Cultural Validation. Journal of Business Venturing, 16: 495-527.

2. Antončič, B. and O. Zorn. 2004. The Mediating Role of Corporate Entrepreneurship in the Organizational Support-Performance Relationship: An Empirical Examination. Managing Global Transitions, 21: 5-14.

3. Asgharpour, M.J. 2008. Multi Criteria Decision Making. Sixth edition: Tehran University Press, p: 78 (In Persian).

4. Ahmadi, F., K. Nasiriani and P. Abazari. 2008. The Delphi technique: a research tool. Journal of Medical Education, 8(1): 185-175 (In Persian).

5. Adeli, A. 2013. Evaluation and interpretation of policies of five-year developmental plans and Iran fisheries outlook. Fisheries Science and Technology, 2(3): 57-74 (In Persian).

6. Amirkabiri, A. and O. Moahmoudian. 2007. The effects of organizational factors on the potential outcomes of entrepreneurship within the organization: research in Categories of information and communications technology industry. Knowledge Management, 79: 127-144 (In Persian).

7. Bhardwaj, B.R. and M.K. Sushil. 2005. Corporate Entrepreneurship: Application of Moderator Method. Singapore Management Review, 2913: 47-58.

8. Certo, S. and M.T. Trevis. 2008. Social entrepreneurship: Key issues and concepts. Business Horizons, 51: 267-271.

9. Chaka, C. 2006. Factors That Promote Corporate Entrepreneurship within the First Rand Bank. Degree of Master of Business Administration. November, p: 163.

10. Chang, D.Y. 1996. Applications of the extent analysis method on fuzzy AHP. European journal of operational research, 95.649-655.

11. Dehghan, R., K. Talebi and A. Arabioun. 2012. Organizational Entrepreneurship And Innovation At Medical Sciences Universities of Iran. Health Pyavrd, 6(1): 22-33 (In Persian).

12. Fisscher, O., D. Frenkel, Y. Lurie and A. Nijhof. 2005. "Stretching the Frontiers: Exploring the Relationships between Entrepreneurship and Ethics. Journal of Business Ethics, 60: 207-209.

13. Fremont, E. 2005. Fundamentals of Organization Behavior. South- Westem college Publishing, p: 49.

14. Firouzyar, S. and D. Kia Kojouri. 2013. Identification of Structural Restricting and Driving Factors of Development of Corporate Entrepreneurship CE: A Case Study. Journal of Entrepreneurship and Innovation Management. 23: 1-16 (In Persian).

15. Gogus, O. and T.O. Boucher. 1997. A consistency test for rational weights in multi-criterion decision analysis with fuzzy pairwise comparisons. Fuzzy Sets and Systems, 862. 129-138.

16. Hornsby, J.S., D.F. Kuratko and S.A. Zahra. 2002. Middle managers perception of the internal environment for corporate entrepreneurship: Assessing a measurement scale. Journal of Business Venturing, 17: 253-273.

17. James, P. 1998. Organization Structure. Pacific Sociological Review, 20: 2.

18. Khampanya, W. and V. Thanaphol. 2010. An Investigation of Ethical Dilemmas and Entrepreneurial Behavior in Established Firms, Agse, 1021-1033.

19. Kuratko, D.F., J.S. Hornsby and L.M. Corso. 1996. Building an adaptive firm. Small Business Forum, 141: 41-48.

20. Kuratko, D., J.S. Hornsby and J. Bishop. 2005. Managers' Corporate Entrepreneurial Actions and Job Satisfaction. International Entrepreneurship and Management Journal, 1: 275-291.

21. Kearney, C., R. Hisrich and F. Roche. 2008. A conceptual model of public sector corporate entrepreneurship. Entrepreneurship Management Journal, 4: 295-313.

22. Karimi, A., R. Rezaei, M. Ahmadpour and M. Ansari. 2013. The Impact of Corporate Culture on Entrepreneurial Trends (Case Study: Agricultural and Natural Resources Campus of Tehran University). Journal of Entrepreneurial Development, 6(3): 163-182 (In Persian).

23. Kearney, C., R. Hisrich and F. Roche. 2009. Public and private sector entrepreneurship: similarities, differences or a combination?. Journal of Small Business and Enterprise Development, 161: 26-46.

24. Laarhoven, P.M. and W. Pedrycz. 1983. A Fuzzy Extension of Saaty s Priority Theory. Journal of Fuzzy Sets and Systems, 111: 229-241.

25. Moghimi, S.M. 2007. Corporate Entrepreneurship: Obstacles and Alternatives The Case of Industrial Corporations in Iran. Journal of Entrepreneurship Research, 119-87 (In Persian).

26. Nunnally, J.C. 1978. Psychometric theory. McGraw-Hill, New York, p: 65.

27. Obino Mokaya, S. 2012. Corporate Entrepreneurship and Organizational Performance: Theoretical Perspectives, Approaches and Outcomes. International Journal of Arts and Commerce, 14: 133-143.

28. Pinchot, G. 1985. Intrapreneuring. New York: Harper and Row Publishers, p: 214.

29. Sadler, R.J. 2000. Corporate entrepreneurship in the public sector: the dance of the chameleon. Australian Journal of Public Administration, 592: 25-43.

30. Sarabi, A., M. Abdouvi and Z. Forotani. 2012. Identify the factors influencing entrepreneurial behavior in the Iranian government. Journal of Organizational Behavior, 2(1): 86-108 (In Persian).

31. Scheepers, M.J., J.C. Hough and J.Z. Bloom. 2008. Nurturing the corporate entrepreneurship capability. Southern African Business Review, 123: 50-75.

32. Srivastava, N. and A. Agrawal. 2010. Factors supporting corporate entrepreneurship: An exploratory study. The Journal of Business Perspective, 14: 163-171. 
33. Tajeddini, K., M. Trueman and G. Larsen. 2006. Examining the Effect of Market Orientation on Innovativeness. Journal of marketing management, 225(6): 529-551 (In Persian).

34. Zampetakis, L.A. and Moustakis. 2007. Entrepreneurial behavior in the Greek public sector. International Journal of Entrepreneurial Behavior and Research, 13: 19-38.

35. Zerbinati, S. and S. Vangelis. 2005. Entrepreneurship in the public sector: a framework of analysis in European local governments. Entrepreneurship and Regional Development, 43-64. 


\title{
Verification and Ranking of Effective Structural Indicators on Entrepreneurship Process by using Fuzzy Delphi and FAHP Approach in Mazandaran Fisheries Organization
}

\author{
Hossein Samadi-Miarkolaei ${ }^{1}$ and Hamzeh Samadi-Miarkolaei ${ }^{2}$ \\ 1- Master of Public Administration, Young Researcher and Elite Club, Islamic Azad University, Qaemshahr, Iran \\ (Corresponding Author: hossein_samadi_m@yahoo.com) \\ 2- Ph.D. of Public Administration, Department of Public Administration, Science and Research Branch, Islamic Azad \\ University, Tehran, Iran \\ Received: September 18, 2017 \\ Accepted: May 12, 2018
}

\begin{abstract}
Organizational entrepreneurship is the process by which organizations identify opportunities for growth and development and create new value for customers through innovation and reallocation of resources. Meanwhile, the structural indicators are the crucial and influential factors on the development of the organizational entrepreneurship process. The purpose of the present research is the verification and ranking of the effective structural indicators on organizational entrepreneurship process in Mazandaran fisheries organization. This study, in terms of research purposes, is an applied research and the used method in this study, in terms of data collection, is the descriptive-survey. Statistical population of the present study includes the experts and experienced professionals in Mazandaran fisheries organization. In the present study, by means of literature review, the effective structural indicators on organizational entrepreneurship were identified. Data collection was conducted using Delphi and paired comparisons questionnaires, and data analysis was done using Fuzzy Delphi method and FAHP. Results of the experts' opinions analysis indicated that among the 16 extracted indicators from research literature, only seven indicators are recognized as influential factors on the entrepreneurship process. Using FAHP, then, the indicators ranked as following: organizational structure (0.507); organizational strategy (0.279); reward systems (0.110); strategies and organizational policies $(0.071)$; human resources system $(0.020)$; organization financial system (0.010); and information resources system (0.004). The managers of this organization, according to these results, must establish a dynamic and flexible structure toward creation and innovation development, and consequently, entrepreneurship encouragement. They must endeavor to take steps to reach a strong and common entrepreneurial strategic vision between themselves and their staffs.
\end{abstract}

Keywords: Organizational Entrepreneurship, Mazandaran Fisheries Organization, Fuzzy Delphi, Fuzzy AHP 